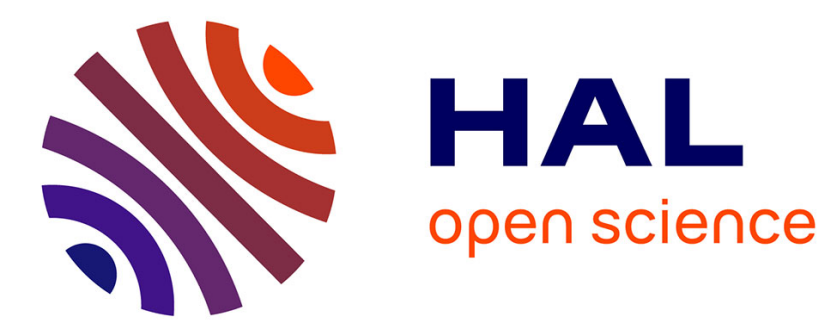

\title{
Pitting Resistance of Pure Fe-17\%Cr Alloys : Consequences for Localized Corrosion Modeling
}

\author{
C. Boulleret, J.-L. Pastol, J. Bigot, B. Baroux, D. Gorse
}

\section{To cite this version:}

C. Boulleret, J.-L. Pastol, J. Bigot, B. Baroux, D. Gorse. Pitting Resistance of Pure Fe-17\%Cr Alloys : Consequences for Localized Corrosion Modeling. Journal de Physique IV Proceedings, 1995, 05 (C7), pp.C7-415-C7-422. 10.1051/jp4:1995751 . jpa-00254046

\section{HAL Id: jpa-00254046 https://hal.science/jpa-00254046}

Submitted on 1 Jan 1995

HAL is a multi-disciplinary open access archive for the deposit and dissemination of scientific research documents, whether they are published or not. The documents may come from teaching and research institutions in France or abroad, or from public or private research centers.
L'archive ouverte pluridisciplinaire HAL, est destinée au dépôt et à la diffusion de documents scientifiques de niveau recherche, publiés ou non, émanant des établissements d'enseignement et de recherche français ou étrangers, des laboratoires publics ou privés. 


\title{
Pitting Resistance of Pure Fe-17\% Cr Alloys: Consequences for Localized Corrosion Modeling
}

\author{
C. Boulleret, J.-L. Pastol, J. Bigot, B. Baroux* and D. Gorse \\ CECM-CNRS, 15 rue Georges Urbain, 94407 Vitry-sur-Seine, France \\ * Centre de Recherche d'Ugine, 73400 Ugine, France
}

\begin{abstract}
Pitting corrosion was observed on a high purity $\mathrm{Fe}-17 \mathrm{Cr}$ alloy in $0.02 \mathrm{M} \mathrm{NaCl}$ solution of pH 6.6 at high anodic potential $(+550 \mathrm{mV} / \mathrm{SCE}$ ). Potentiostatic electrochemical noise measurements were performed, revealing the presence of a characteristic current noise below stable pitting, differing strongly from that observed on a series of AIST 430 type $17 \% \mathrm{Cr}$ stainless steels, with respect to the frequency of occurrence and shape of the metastable events. These rather small, infrequent and long-lived events exhibit a sudden increase followed by a slow decrease with a decay time $\sim 100 \mathrm{~s}$. Arguments are given in favor of a pit initiation process occurring at some weak points of the passive film, distinct from scratches. In the light of the present study, analysis of previous results obtained on some AISI 430 type inclusions containing industrial stainless steels reveal that, after a certain polarization time, pitting may also occur by local breakdown of the passive film.
\end{abstract}

\section{INTRODUCTION}

Resistance to pitting corrosion of high purity metals or alloys is far from being clearly understood. Pitting corrosion of ultra-pure iron was studied in the early seventies by Janick-Czachor [1]. During the following period, contrary to what could have been expected, resistance to pitting corrosion has been mostly studied on industrial alloys rather than on pure metal or alloys.

In the case of industrial alloys, pitting corrosion is generally associated with the presence of surface heterogeneities, in the form of inclusions. It is well known that metastable pitting (pit initiation followed by repassivation) leads to an intense electrochemical potential or current noise which has been shown to be related to the type of inclusions present in the steel. A number of studies have dealt with the role of manganese sulphide on the susceptibility to pitting of stainless steels. Moreover, we have shown recently that the shape of the metastable pitting events is the signature of the type of heterogeneity acting as pitting site $[2,3]$.

Most of the work concerning the resistance to pitting of pure alloys was performed by Bertocci et al. [4] in the eightics. However, a lack of precision concerning the impurity contents and a poor surface finish make certain results in the literature difficult to interpret : for example, in the case of samples noted to have been prepared by vacuum melting, the composition and the polishing conditions are in some cases not even mentioned. As an alternative to ultra-pure materials, sputter deposited alloys have been more recently extensively studied, with the drawback that this method is a source of other kinds of flaws originating from density variations, of changes of local order in the uppermost layers of the thin metal film.

Now, pitting experiments performed on pure alloys without inclusions are nceded for pit initiation modelling. In this paper, our purpose is to study the pitting resistance of a high purity Fe-17\% $\mathrm{Cr}$ alloy by means of potentiostatic electrochemical noise measurements performed in a range of potentials below the pitting potential. When necessary, comparison will be made with the results of a previous study on a series of industrial AISI 430 type $17 \%$ Cr ferritic stainless steels, with various additions of Ti and S [3]. 


\section{EXPERIMENTAL}

\subsection{Materials investigated}

High purity FC-17Cr alloy was prepared at the CECM. The iron powder (Johnson-Matthey) is compressed separately into pellets, and melted in a helium atmosphere to form a bar, which undergoes five passes of horizontal zone-melting in helium. This bar is zone-refined five times in purified dry hydrogen [5]. The starting electrolytic chromium undergoes four $(3+1)$ passes of horizontal zone-melting in hydrogen. This treatment is followed by $20 \mathrm{~h}$ annealing at $1300^{\circ} \mathrm{C}$ in hydrogen [6]. Iron and chromium are then melted in helium at $\sim 1600^{\circ} \mathrm{C}$. The ingots obtained were directly sliced into $\sim 1 \mathrm{~mm}$ thick specimens of diameter varying between 5 and $7 \mathrm{~mm}$.

Inductively Coupled Plasma Atomic Emission Spectrometry (ICP-AES) is a suitable method for rapidly determining a large number of impurities with sufficient accuracy in a given material [7]. The results of analysis by ICP-AES are reported in Table 1 . The concentrations of the major components were also determined by ICP-AES using the same experimental procedure and parameters as in [8], except for the integration time $(2 \mathrm{~s})$ and the nebulizer pressure $(33 \mathrm{psi})$. The alloy was dissolved in $0.7 \mathrm{~N} \mathrm{HCl}+0.5 \mathrm{~N}$ $\mathrm{HNO}_{3}$, solutions of known concentrations of $\mathrm{Fe}$ or $\mathrm{Cr}$ in the same acid concentration solution and blanks with the same acid concentration being used for calibration [8]. Minor elements were analyzed by comparison with standard solutions containing a concentration of $10 \mathrm{mg} / \mathrm{l}$ of the chosen element. The $\mathrm{C}, \mathrm{O}$, $\mathrm{N}$ contents were respectively evaluated directly from the corresponding $\mathrm{C}, \mathrm{O}$ and $\mathrm{N}$ concentrations measured in the purified $\mathrm{Fe} \mathrm{[5]} \mathrm{and} \mathrm{Cr}$ (after 3 passes of zone-melting in this case) [6]. These alloys were all thoroughly investigated by SEM : as expected, no inclusion on any specimen was detected.

Table 1 Concentrations of impurities in the Fe-17Cr alloy, in $\mathrm{ppm}$ unless otherwise specified.

\begin{tabular}{ccccccccccc}
\hline $\mathrm{Fe}(\mathrm{wt} . \%)$ & $\mathrm{Cr}(\mathrm{wt} . \%)$ & $\mathrm{Ag}$ & $\mathrm{Al}$ & $\mathrm{Ce}$ & $\mathrm{Cu}$ & $\mathrm{Ga}$ & $\mathrm{Mg}$ & $\mathrm{Mn}$ & $\mathrm{Na}$ & $\mathrm{Nb}$ \\
\hline $83.5 \pm 0.8$ & $16.7 \pm 0.2$ & $<0.2$ & $<0.3$ & $<0.5$ & $<0.05$ & $<0.5$ & $<0.003$ & $<0.01$ & $<1$ & $<0.5$ \\
\hline & & & & & & & & & & \\
\hline $\mathrm{Ni}$ & $\mathrm{P}$ & $\mathrm{Re}$ & $\mathrm{S}$ & $\mathrm{Si}$ & $\mathrm{Ta}$ & $\mathrm{Ti}$ & $\mathrm{V}$ & $\mathrm{w}$ & $\mathrm{Zn}$ & $\mathrm{Zr}$ \\
\hline$<0.5$ & $<2$ & $<1$ & $<1$ & $<1$ & $<1$ & $<0.01$ & $<0.2$ & $<1$ & $<0.2$ & $<0.1$ \\
\hline
\end{tabular}

Table 2 Stcels composition in wt.\% or in ppm (brackets).

\begin{tabular}{ccccccccccccc}
\hline & $\mathrm{Cr}$ & $\mathrm{Ni}$ & $\mathrm{Si}$ & $\mathrm{Mn}$ & $\mathrm{Ti}$ & $\mathrm{Nb}$ & $(\mathrm{S})$ & & $(\mathrm{C})$ & (N) & $(\mathrm{O})$ \\
\hline steel A & 16.63 & 0.092 & 0.408 & 0.444 & 0.003 & 0.498 & 60 & 210 & 300 & 119 \\
\hline steel B & 17.40 & 0.102 & 0.358 & 0.437 & 0.364 & $<0.002$ & 47 & 250 & 110 & 34 \\
\hline
\end{tabular}

The electrochemical results obtained with the so alloy obtained were in some cases compared to results obtained during the study of a series of industrial AISI 430 type ferritic stainless steels [3], containing controlled amounts of sulfur and titanium. The compositions of two of them, respectively referred to as steel A stabilized with $\mathrm{Nb}(0.003$ wt.\% Ti, $0.498 \mathrm{wt} \% \mathrm{Nb})$, and steel B stabilized with Ti (0.364 wt.\% Ti, $<0.002 \mathrm{wt} . \% \mathrm{Nb}$ ) are given in Table 2 .

\subsection{Sample preparation and electrochemical conditions}

Particular attention was paid to surface preparation, since residual scratches may also initiate pits. Two mechanical polishing procedures were tested, one using successively finer grades of abrasive SiC paper (300 to 1200) and then $3 \mu \mathrm{m}, 1 \mu \mathrm{m}$ diamond paste, the other employing only diamond paste from $30 \mu \mathrm{m}$, to $10 \mu \mathrm{m}, 3 \mu \mathrm{m}$ and then $1 \mu \mathrm{m}$. The former method was rapidly abandoned, giving too poor a surface condition as we shall see below. The surface morphology of the polished sample surface was examined (after testing, ex-situ) in an AFM (commercial Atomic Force Microscope instrument, Park) and a SEM. Indeed, it was found that the surface roughness of samples solely polished with diamond paste, $\Delta \mathrm{h} \sim 100$ $\AA$ (peak to valley), was reduced at least by a factor of 3 to 4 , by comparison with that obtained for surfaces polished on SIC papers, where deep scratches are clearly visible.

After polishing, ultrasonic degreasing in alcohol-acetone and final rinsing, the samples were exposed for $24 \mathrm{~h}$ in air prior to testing, this air ageing period being necessary to insure the reproducibility of the results. Electrochemical measurements were made using a low noise EGG 273 potentiostat with computer control. A standard two-compartment electrochemical cell was used with a $\mathrm{Pt}$ counter electrode and a saturated calomel reference electrode (SCE), the solution $(200 \mathrm{ml})$ being degassed with purified nitrogen in a separate 
compartment. Measurements are carried out at room temperature in deaerated and stagnant $0,02 \mathrm{M} \mathrm{NaCl}$ solution at $\mathrm{pH}$ 6.6. Two different exposed areas were used for the study $\left(9.6 \mathrm{~mm}^{2}\right.$ and $\left.35.3 \mathrm{~mm}^{2}\right)$. The samples were maintained at open circuit potential for $30 \mathrm{~min}$. Then, the potential was imposed by stepping up to one value below the pitting potential, and the unfiltered anodic current fluctuations were recorded, with a sampling time equal to 0.06 seconds.

\section{RESULTS}

High purity $\mathrm{Fe}-17 \mathrm{Cr}$ alloys are susceptible to pitting corrosion. Below stable pitting, a certain electrochemical activity is observable in the not very strong solution chosen in this work, taking the form of rather well spaced metastable events : this so-called electrochemical noise is studied in the following, with special emphasis given to all points of difference with the potentiostatic current noise observed on industrial alloys, especially the $17 \% \mathrm{Cr}$ ferritic stainless steels previously studied in the same electrochemical conditions.

\subsection{Pitting potential and potential dependence of the electrochemical noise}

These are the only two points of comparison with stainless steels, and particularly with the series of AISI 430 type $17 \% \mathrm{Cr}$ ferritic stainless steels containing controlled amounts of sulphur (from $8 \mathrm{ppm}$ to $47 \mathrm{ppm}$ ) and titanium (from $0.005 \mathrm{wt} . \%$ to $0.364 \mathrm{wt} . \%$ ) previously studied, as reported in [3]. All experiments were conducted in potentiostatic conditions. In this work, the potentials applied vary from +450 mV/SCE to $+550 \mathrm{mV} / \mathrm{SCE}$. On high purity $\mathrm{Fe}-17 \mathrm{Cr}$ alloy, it is found that a stable pit develops during the first minutes of exposure in solution when the potential applied attains $+550 \mathrm{mV} / \mathrm{SCE}$. This result being reproducible, the pitting potential $V_{p}$ was fixed at $+550 \mathrm{mV} / \mathrm{SCE}$ : this value of $\mathrm{V}_{\mathrm{p}}$ is much higher than those found on the series of stainless steels studied in [3]: i) higher than the pitting potential obtained by decreasing the sulfur content from $41 \mathrm{ppm}$ to $8 \mathrm{ppm}$ for which $\mathrm{V}_{\mathrm{p}}$ was found equal to $+400 \mathrm{mV} / \mathrm{SCE}$, ii) higher than the pitting potential obtained by increasing the content in the Ti stabilizing element trapping not only $\mathrm{C}$, but also $\mathrm{N}$ and above all $\mathrm{S}$ in the form of Ti sulfides during the steel making process, leading to a value of $V_{p}=t$ $500 \mathrm{mV} / \mathrm{SCE}$ for steel $\mathrm{B}$, as noted above. We recall that the pitting potential, determined either potentiostatically or potentiokinetically during statistical testing, has been shown to be increased by either increasing the titanium content, or decreasing the sulphur content $[3,9]$.

Moreover, the potential range over which metastable events can be observed is rather limited, appearing only $10 \mathrm{mV}$ below $V_{p}$ : electrochemical noise was only observed for the applied potentials $V_{a}=+540$ $\mathrm{mV} / \mathrm{SCE}$ and $+545 \mathrm{mV} / \mathrm{SCE}$. Below, for $\mathrm{V}_{\mathrm{a}}=+530 \mathrm{mV} / \mathrm{SCE}$, the anodic current decreases monotonously with polarization time, no metastable pitting event being observable over the test duration. If any potential dependence of the electrochemical noise is visible, it is worth noting that it concems only a few $m V$ below $V_{p}$.

At this point, and referring to the absence of visible inclusions during the SEM and AFM investigations, it is noticeable that surface heterogeneities such as manganese sulfide are not a necessary condition for pit initiation.

By comparison, for the series of stainless steels noted above, the potential range of observable current fluctuations decreases from $180 \mathrm{mV}$ to $50 \mathrm{mV}$ when the sulphur content decreases from $41 \mathrm{ppm}$ to $8 \mathrm{ppm}$, without any other change in the composition of the successive alloys tested. But note that for all compositions, even if the inclusions are at the same time rarefied and made "purer" (one or two phases identified : for example, of type $\mathrm{Al}_{2} \mathrm{O}_{3}$ surrounded by $\mathrm{NbC}$ ) by decreasing the sulphur content to $8 \mathrm{ppm}$, nevertheless, there are still some remaining, possibly acting as pitting initiation sites.

\subsection{Frequency of occurrence and shape of the electrochemical noise}

As for industrial alloys, a "prepitting" noise is visible on high purity alloys, below stable pitting. But this noise exhibits some characteristic features generally not observed when active inclusions are present at the surface of the material, such as the widely studied manganese sulphide inclusions present in a variety of stainless steels, provided that the level of titanium be not sufficient to prevent the formation of any of these very unstable inclusions $[3,9,10]$. Under the same electrochemical conditions $(\mathrm{pH} 6.6$, dilute chloride solution), the behavior of the $\mathrm{Fe}-17 \mathrm{Cr}$ alloy contrasts remarkably with that of any stainless steel previously studied. It concerns all measurable points : frequency of occurrence of the events, shape of the events, evolution of the events with applied potential and polarization time. 


\subsubsection{Frequency of occurrence of the events}

The first remarkable difference with Ti-free stainless steels exhibiting unstable inclusions is that, on a high purity alloy, it is possible to count the number of events, which is unthinkable as an example for Ti free stainless steels especially when approaching the pitting potential, for which only a spectral analysis can be performed. The second noticeable point is that generally the first event appears under polarization after a few minutes of exposure in solution, (exactly $6 \mathrm{~min} 45$ in Fig. 1.b). Last, still for the high purity $\mathrm{Fe}-17 \mathrm{Cr}$ alloy, there is no evidence of any reduction of the surface "activity" with increasing exposure time, as seen in Fig. 1.c and 2.b after 1 hour polarization time in both cases. This result is in marked contradiction to those frequently obtained on stainless steels for which the polarization time markedly influences the frequency of occurrence and also the shape of the events as already observed [3]. As regards the frequency of occurrence of the events, the only observable influence of applied potential is that increasing $V_{2}$ from $+540 \mathrm{mV} / \mathrm{SCE}$ to $+545 \mathrm{mV} / \mathrm{SCE}$ doubles the number of observable events $:$ it is of the order of a few tens after one hour of polarization time within a few $\mathrm{mV}$ from the pitting potential.

\subsubsection{Shape of the metastable events}

In this paper, three kinds of metastable events are reported, as seen in Figs. 1 to 4 . Associated with increasing orders of total duration of the "birth and death" events, we have : i) short almost symmetrical events typical of scratches (Fig.3.b), ii) events of type I according to the recent literature $[3,10,11]$, characterized by a "slow" increase and sharp decrease, commonly observed and largely studied in a wide range of inclusions containing materials (Fig. 4.a), iii) events of type II, characterized by a sudden increase followed by a smooth decrease, the only ones observable on high purity alloys (Fig. 1.b, 1.c, 2.b), but also observed on stainless steels provided that the samples are "sufficiently aged" (Fig. 4.b and 4.c), once the inclusions are no longer active, being either dissolved or passivated.

We concentrate now on the shape of the events detected on the $\mathrm{Fe}-17 \mathrm{Cr}$ alloy. As stated above, a limited number of metastable pitting events is observed, with "short" rise time $\left(0.18 \mathrm{~s} \leq \tau_{i} \leq 3 \mathrm{~s}\right)$ and in all cases long decay time (from a few tens of seconds to 150 seconds). Moreover, the charge carried in all these events is generally small. But we may further discriminate between 1) very small events most frequently observable at $+540 \mathrm{mV} / \mathrm{SCE}$ (rarely at $+545 \mathrm{mV} / \mathrm{SCE}$ ), an example of which is shown in Fig. $1 . \mathrm{b}$, with a charge ranging from $10 \mathrm{nC}$ to $50 \mathrm{nC}$, a really "short" rise time $\left(0.18 \mathrm{~s} \leq \tau_{\mathrm{i}} \leq 0.36 \mathrm{~s}\right)$ and a not too long decay time $\left(5 \mathrm{~s} \leq \tau_{\mathrm{d}} \leq 20 \mathrm{~s}\right)$, 2) larger events rather infrequent at $+540 \mathrm{mV} / \mathrm{SCE}$ (Fig. 1.c) but frequent at $+545 \mathrm{mV} / \mathrm{SCE}$, with a charge ranging from $100 \mathrm{nC}$ to $350 \mathrm{nC}$, a "short" rise time $\left(0.18 \mathrm{~s} \leq \tau_{\mathrm{i}} \leq 3 \mathrm{~s}\right)$ and a longer decay time $\left.\left(20 \mathrm{~s} \leq \tau_{\mathrm{d}} \leq 100 \mathrm{~s}\right), 3\right)$ the largest events whose charge may attain $800 \mathrm{nC}$, with a decay time attaining $150 \mathrm{~s}$ (Fig. 2.b). As the pitting potential is more closely approached, combinations of these simple events are sometimes visible, which may be described as multi-events (none is shown). It is also noticeable that, in general, the increasing time $\left(\tau_{i}\right)$ appears slightly longer at the higher applied voltage. Further, the decay curve cannot be fitted by a single exponential $\left(\exp (-\mathrm{t} / \tau)\right.$ or any simple power law $\mathrm{t}^{-n}$. It is suggested that part of the repassivation charge is supplied by the passive surface surrounding the pit. Above all, it is clear that the polarization time has no significant influence on the shape of the events.

Three points are remarkable. First note that these decay times differ from those detected by Bertocci et al. for Fe-12Cr or Fe-20Cr alloys (ranging from $10 \mathrm{~ms}$ to $550 \mathrm{~ms}$ ) [4]. By comparison, in our study of AISI 430 type stainless steels [3], short events of lifetime not exceeding $0.5 \mathrm{~s}$ were also observed on the $0.364 \mathrm{wt} . \%$ Ti-bearing alloy (steel B in Table 2), but only in the case of poor surface finish obtained when polishing the surface with SiC papers, whereas when using only diamond polishing absolutely no noise of type (i) or (ii) can be detected below stable pitting : events of such frequency of occurrence (see Fig. 3.a) and shape (Fig. 3.b) may thus be clearly associated with the presence of residual cracks due to the polishing procedure. This result was confirmed by SEM and AFM observations. As a consequence, it is stated that the "prepitting" events detected in this work on high purity Fe-17Cr cannot be induced by scratches on the surface. This point is confirmed by the fact that no pit initiated at a scratch is observable with SEM and $\mathrm{AFM}$ on high purity $\mathrm{Fe}-17 \mathrm{Cr}$ samples.

Moreover, it is remarkable that no metastable pit can be detected by either of these two techniques on the high purity Fe-17Cr samples. At the higher voltage, where stable pits have been shown to propagate, SEM and AFM have revealed the presence of well developed pits.

The second noticeable point is the absence of any current fluctuations in the first minutes of exposure in solution over the whole potential range studied up to pitting (Fig 1.a, Fig 2.a). Once again, these findings contrast markedly a priori not only with the results obtained on samples with a poor quality surface finish (see for example steel B in Fig. 3.a, where intense noise is visible from the beginning of the experiment), but also with current results obtained on inclusions containing steels for which the activity of the surface reaches its maximum within a few minutes following imposition of the potential. This trend is nicely followed by steel $\mathrm{A}$ in Fig. 4.a, as for a number of previously published results. For example, we may 

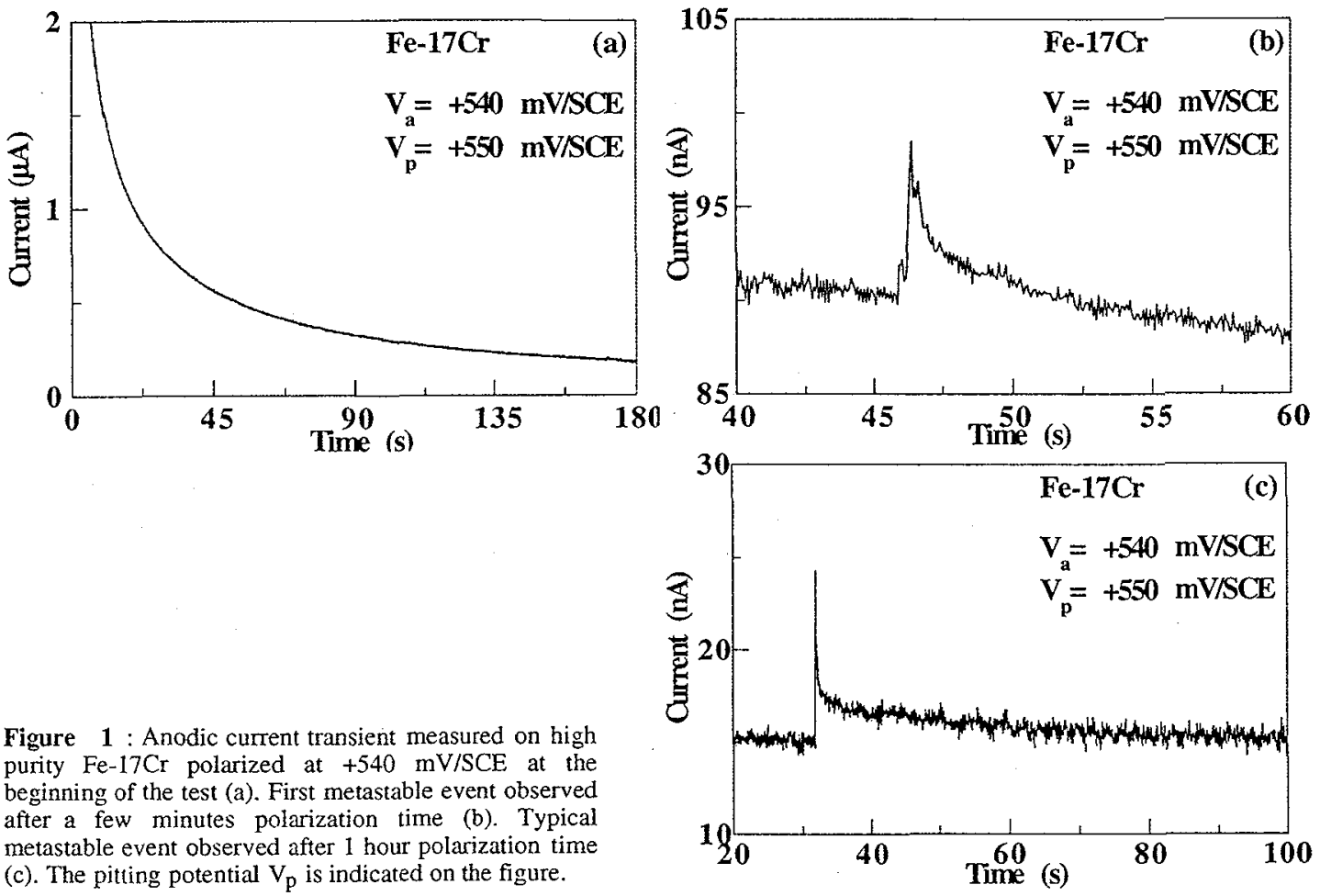

Figure 1 : Anodic current transient measured on high purity $\mathrm{Fe}-17 \mathrm{Cr}$ polarized at $+540 \mathrm{mV} / \mathrm{SCE}$ at the beginning of the test (a). First metastable event observed after a few minutes polarization time (b). Typical metastable event observed after 1 hour polarization time (c). The pitting potential $\mathrm{V}_{\mathrm{p}}$ is indicated on the figure.
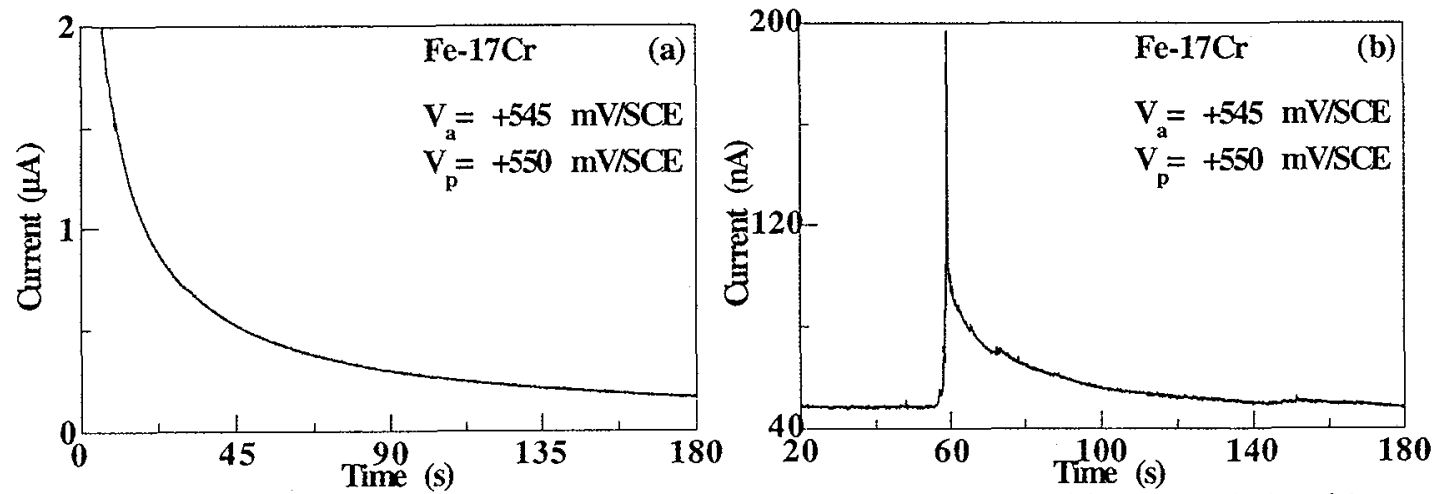

Figure 2 : Anodic current transient measured on high purity $\mathrm{Fe}-17 \mathrm{Cr}$ polarized at $+545 \mathrm{mV} / \mathrm{SCE}$ at the beginning of the test (a). Typical metastable event observed after 1 hour polarization time (b). The pitting potential $\mathrm{V}_{\mathrm{p}}$ is indicated on the figure. 

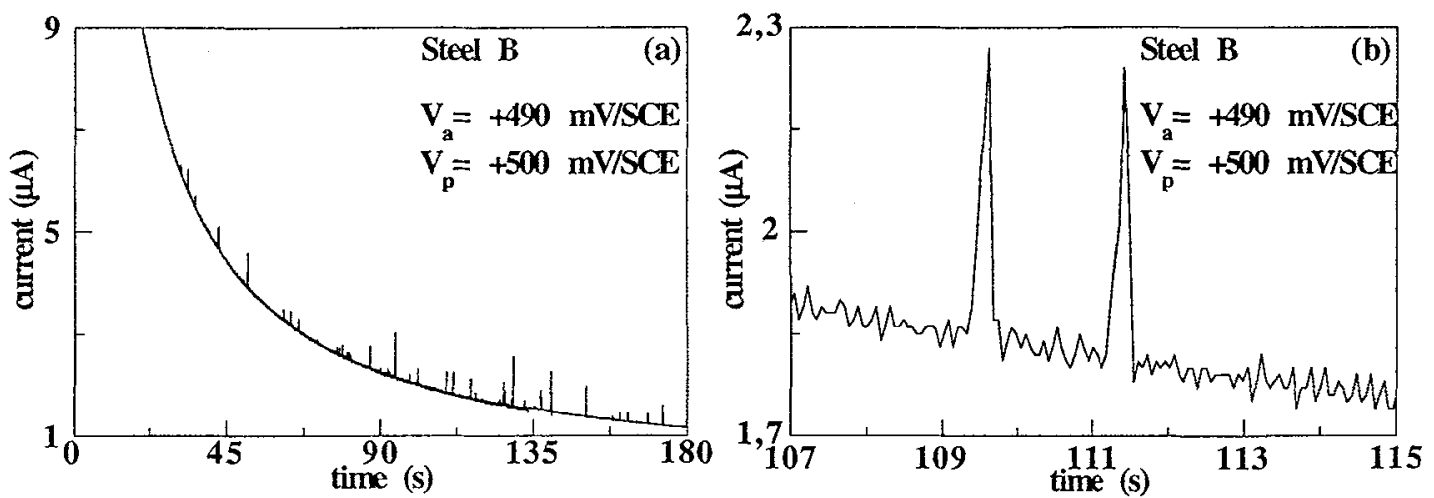

Figure 3: Anodic current transient measured on a 0.364 wt.\% Ti bearing steel B, polished on various SiC papers to 1200 grade then using $3 \mu \mathrm{m}$ and $1 \mu \mathrm{m}$ diamond paste, showing well visible scratches on the surface, polarized at $+490 \mathrm{mV} / \mathrm{SCE}$ at the beginning of the test (a). An expansion of the region from $107 \mathrm{~s}$ to $115 \mathrm{~s}$ showing two short-lived events characteristic of the presence of scratches on the surface (b). The pitting potential $V_{p}$ is indicated on the figure.
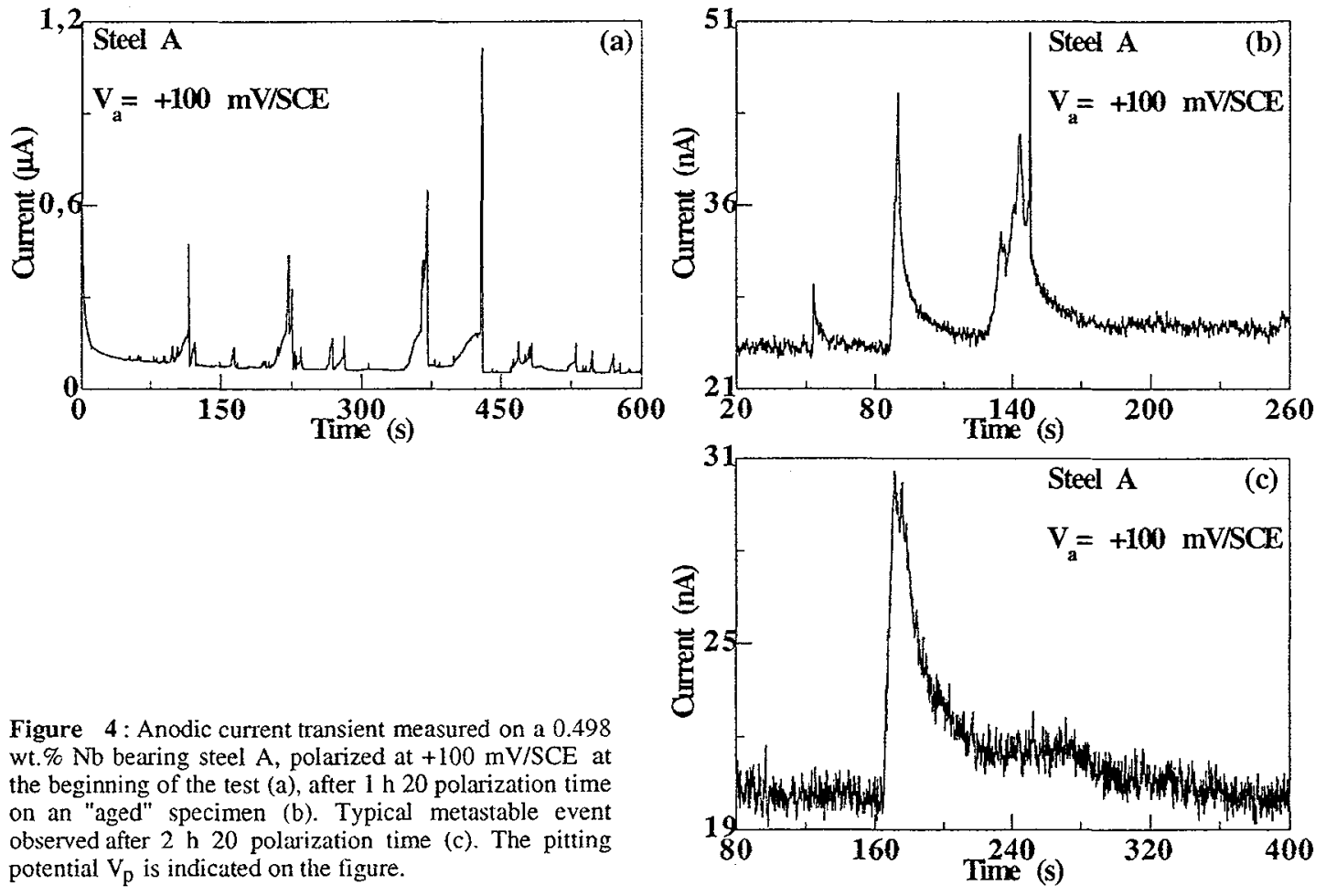

Figure $4:$ Anodic current transient measured on a 0.498 wt. \% $\mathrm{Nb}$ bearing steel $\mathrm{A}$, polarized at $+100 \mathrm{mV} / \mathrm{SCE}$ at the beginning of the test (a), after $1 \mathrm{~h} 20$ polarization time on an "aged" specimen (b). Typical metastable event observed after $2 \mathrm{~h} 20$ polarization time (c). The pitting potential $V_{p}$ is indicated on the figure. 
quote those obtained on a Ti free 41 ppm sulphur containing steel under similar experimental conditions [3].

Thus, apparently, the incubation time for initiation of the first metastable event of type II on the high purity Fe-17Cr alloy is noticeably enlarged, by compatison with industrial alloys exhibiting type I events corresponding to metastable pits nucleated at the various possible inclusion sites depending on the chloride content and $\mathrm{pH}$ of the aqueous solution.

The third noticeable point is that, once they become visible on the $\mathrm{Fe}-17 \mathrm{Cr}$ alloy, these events exhibit a shape closely resembling that obtained in similar electrochemical conditions after a "certain ageing time" on various inclusions containing steels [10], an example of which is reported here with steel A after respectively $1 \mathrm{~h}$ (Fig. 4.b) and $2 \mathrm{~h} 20$ (Fig. 4.c) of polarization time. Moreover, the charge carried by the type II events obtained on steel $\mathrm{A}$ is of the same order of magnitude as that carried by similar events found on the $\mathrm{Fe}-17 \mathrm{Cr}$ alloy in similar electrochemical conditions. The only differences between steel $\mathrm{A}$ and the high-purity alloy come from 1$)$ a rise time found to be slightly longer for steel $\mathrm{A}\left(0.6 \mathrm{~s}<\tau_{\mathrm{i}} \leq 5 \mathrm{~s}\right)$, and 2) from a longer decay time which may attain $\tau_{\mathrm{d}} \sim 200 \mathrm{~s}$ on Steel $\mathrm{A}$ in some cases. Further it was observed that the overlapping of period with type I events and that with type II events is reduced to a few minutes. Thus, it is possible to speak of "a transition" between two regimes of current fluctuations, in which the shape of the metastable events changes from type I to type II.

These last three points concerning both the incubation time for pit nucleation and the shape of the events suggest that metastable pits found on the high purity $\mathrm{Fe}-17 \mathrm{Cr}$ alloy may be directly initiated at some points, distinct from scratches, in the passive film which has been locally modified during the incubation period. A pitting mechanism based on the nucleation of $2 \mathrm{D}$ halide islands would not be inconsistent with these results [12]. However, other pitting models do not require any other source of heterogeneity than that pertaining to the passive film itself, assuming that breakdown of the passive film occurs by electrostriction [13] when the surface tension has sufficiently decreased by absorption of $\mathrm{Cl}^{-}$, this effect being dependent on the local curvature radius of the surface [14]. This hypothesis of pits starting at weak spots of the passive film could be supported by the fact that events similar in shape and charge have been found not only on the "aged" passive films formed on steel A under polarization but also on different types of aged passivated steels for which the nature and distribution of inclusions differ significantly [10]. The same hypothesis could also explain the fact that polarization time has no influence either on the frequency of occurrence of the events or on their shape.

\section{CONCLUSION}

Resistance to pitting of a high purity $\mathrm{Fe}-17 \mathrm{Cr}$ was studied potentiostatically in a neutral chloride solution. It was shown that this high purity alloy is susceptible to pitting and exhibits an electrochemical noise the characteristics of which differ significantly either from the noise detected on a rough steel surface showing clearly visible scratches or from that observed on a series of AISI 430 type 17\% Cr ferritic stainless steels in identical electrochemical conditions when inclusions are active :

- well spaced and long-lived and rather small metastable events are seen;

- these so-called type II events exhibit a sudden increase followed by a smooth decrease;

- the decay time may take more than one hundred seconds;

- the frequency of occurrence and the shape of these events are independent of the polarization time.

The hypothesis is proposed that these events may be initiated at certain weak points in the passive film, locally modified during exposure time in solution. Correlatively, this study shows that inclusions, and especially manganese sulfides are not a necessary condition for pit initiation. For a future work, high purity $\mathrm{Fe}-\mathrm{Cr}$. alloys seems to be good candidates for studying the role of the passive film properties of the pitting process.

\section{Acknowledgments}

The authors gratefully acknowledge the help given by J. C. Rouchaud and M. Fedoroff (CECM) for the analysis of the alloys and by G. Blanc (Ugine) for the AFM study. 


\section{References}

[1] Janik-Czachor M., Br. Corros. J. 6 (1971) 57-60.

[2] Baroux B. and Gorse D., "The Effect of $\mathrm{pH}$ and Potentiostatic Polarization on the Pitting Resistance of Stainless Steels : Relation to Non-metallic Inclusions or Passive Films Modifications", Symposium on Modifications of Passive Films, Paris 15-17 february 1993, P. Marcus, B. Baroux and M. Keddarn Eds. (European Federation of Corrosion Publications, London, 1994) pp. 300-312.

[3] Gorse D., Boulleret C. and Baroux B., "Effect of Metallurgical Factors on the Electrochemical Noise Measured on AISI 430 type Stainless Steels in Chloride Containing Media", ASTM International Symposium on Electrochemical Noise measurements for Corrosion Applications, Montreal 16-17 May 1994, in press.

[4] Bertocci U., Koike M., Leigh S., Qiu F. and Yang G., J. Electrochem. Soc. 133 (1986) 1782-1786.

[5] Faudot F., Rouchaud J.-C., Debove L., Fedoroff M. and Bigot J., J. Phys. Chem. Solids 48 (1987) $761-765$.

[6] Bigot J., Ann. Chim. t. 5 (1970) 397-412.

[7] Fedoroff M. and Rouchaud J.-C.,"Recent Progress in the Analysis of High-Purity Metals", Ultra High Purity Base Metals, Japan 24-27 May 1994, K. Abiko, K. Hirokawa, S. Takaki Eds. (The Japan Institute of Metals, 1994) pp. 210-216.

[8] Rouchaud J.-C., Fedoroff M., Sakout T., Gorse D., Analusis 22 (1994) 49-54.

[9] Baroux B., "Corrosion Mechanisms in Theory and Practice", P. Marcus and J. Oudar Eds, M. Dekker Inc., (New-York 1995) pp. 265-309.

[10] Baroux B., Gorse D., "The respective effects of passive films and non metallic inclusions on the pitting resistance of stainless steels - Consequences on the pre-pitting noise and the anodic current transients", Modeling Aqueous Corrosion From Individual Pits to System Management, 1994, K. R. Trethewey and P. R. Roberge Eds. (Kluwer Academic Publishers, Netherlands, 1994) pp. 161-182.

[11] Gabrielli C., Huet F., Keddam M. and Oltra R., Corrosion 46 (1990) 266-278.

[12] Heusler K.E. and Fisher L., Werkst. Korros. 27 (1976) 551-556.

[13] Sato N., Electrochimica Acta 16 (1971) 1683-1689.

[14] Xu Y., Wang M. and Pickering H.W., J. Electrochem. Soc. 140 (1993) 3448-3457. 